\title{
AMINO ACID SEQUENCES OF HORDEIN POLYPEPTIDES
}

\author{
by \\ JÜRGEN M. SCHMITT* \\ Department of Physiology, Carlsberg Laboratory \\ Gamle Carlsberg Vej 10, DK-2500 Copenhagen Valby \\ and \\ IB SVENDSEN \\ Department of Chemistry, Carlsberg Laboratory \\ Gamle Carlsberg Vej 10, DK-2500 Copenhagen Valby \\ * Present address: Institut für Botanik, Universität Würzburg, FRG.
}

Keywords: Barley, prolamin, carboxy-terminus

Total hordein and purified hordein polypeptides $\mathrm{B} 1$ and $\mathrm{C} 2$ have been analyzed by carboxypeptidase $\mathrm{Y}$ digestion and sequential Edman degradation. The carboxypeptidase $\mathrm{Y}$-catalyzed release of amino acids reveals the sequence (Ile, Ser)-Ser-Met-Val-COOH for the carboxy terminus of the $\mathrm{C} 2$ polypeptide. The same amino acids, with an additional glycine, were released from a total hordein preparation. Glycine has previously been found in the carboxyterminal sequence - Gly- $\mathrm{Val}-\mathrm{COOH}$ of the $\mathrm{B} 1$ polypeptide.

The $\mathrm{B} 1$ polypeptide was blocked to Edman degradation. The $\mathrm{C} 2$ polypeptide yielded a single amino acid sequence: $\mathrm{H}_{2} \mathrm{~N}$-Arg-Gln-Leu-Asn-Pro-Ser-Ser-Gln-Glu-Leu- X -Ser-Pro-Gln-Gln-Pro-Tyr-Leu-Gln-Gln-ProTyr-Pro-Gln-Asn-... One sequence obtained from the total hordein preparation was identical with the $\mathrm{C} 2$ sequence and proved in addition glutamine to be the amino acid in position 11. This sequence continued with the following residues: $-\stackrel{26}{X}-$ Tyr-Leu-Glu- X -Gly-

More than one amino acid was identified at positions $7,12,15,16,27$ and 31 , suggesting the presence of several hordein polypeptides with very similar $\mathrm{N}$-terminal sequences in the total hordein preparation. If the polymorphisms at these positions have arisen by amino acid substitutions, then seven of the twelve possible substitutions require two nucleotide changes in their codons. We tentatively propose that the amino termini of the hordein polypeptides accessible to Edman degradation are from an evolutionary point of view under functional constraint.

Abbreviations: HPLC $=$ high performance liquid chromatography, $\mathrm{PTH}=$ Phenylthiohydantoin, $\mathrm{SDS}=$ sodium dodecyl sulfate, THEED $=\mathrm{N}, \mathrm{N}, \mathrm{N},{ }^{\prime} \mathrm{N}$,-tetrakis (2-hydroxyethyl)ethylenediamine. 


\section{INTRODUCTION}

The nutritional requirements of germinating barley grains are partially met by the mobilization of endosperm storage proteins. This group of proteins includes prolamin, the name referring to its high proline and glutamine content. The prolamin of barley is called hordein and consists of a mixture of polypeptides which can be resolved by electrophoresis in the presence of sodium dodecyl sulfate and by isoelectric focusing $(14,18,22)$. The hordein precursor polypeptides are translated from different mRNAs (6) on the rough endoplasmic reticulum (8). They are transported through the membrane of the endoplasmic reticulum and deposited in protein bodies after part of the protein chain has been cleaved off $(7,10,25)$.

The recent advances in the understanding of hordein biosynthesis make it important to obtain more precise information on the molecular structure of hordein polypeptides. One distinguishes the $\mathrm{C}$ polypeptides with an apparent molecular weight ranging from 45.000 to 70.000 and the $\mathrm{B}$ polypeptides ranging from 25.000 to 40.000 (14). These two groups of polypeptides are considered to be coded for by two different loci on chromosome $5(12,19,23$, 24). In a recent communication (21) methods for the purification of individual hordein polypeptides have been reported and it was found that the hordein polypeptides $\mathrm{C} 2$ and $\mathrm{B} 1$ differed in the amino acid composition of the total chain as well as their carboxy-terminal sequences. In continuation of this work we present in this paper the amino-terminal sequence and the carboxy-terminal sequence of the $\mathrm{C} 2$ polypeptide. The B1 polypeptide was not accessible to Edman degradation but sequencing of the total hordein fraction revealed the presence of hordein polypeptides differing in their primary structure from the $\mathrm{C} 2$ polypeptide.

\section{MATERIALS AND METHODS}

\subsection{Isolation of total hordein}

Hordein was extracted from barley meal (cv. Bomi) as described previously (21) but with the following modifications: The preliminary waterextraction was omitted. To the first isopropanol medium $1 \%(\mathrm{v} / \mathrm{v})$ of a $100 \mathrm{~mm}$-ethanolamine$\mathrm{HCl}$ solution, $\mathrm{pH} \mathrm{7,} \mathrm{was} \mathrm{added} \mathrm{to} \mathrm{scavenge}$ possible aldehyde impurities. After dialysis against $100 \mathrm{~mm}$-mercaptoethanol, the residue was centrifuged as described previously and the pellet redissolved in 0.51 of $55 \%$ isopropanol, $100 \mathrm{~mm}$-mercaptoethanol, $5 \mathrm{~mm}$-ammonium acetate $\mathrm{pH}$ 7. A $1 \mathrm{ml}$ aliquot, corresponding to 140 nmoles of polypeptide based on an average molecular weight of 40.000 was dried in vacuo and subsequently freeze-dried first from water, then from $1 \%$ acetic acid, and used for sequencing.

\subsection{Purification of hordein polypeptides $\mathrm{C} 2$ and $B 1$}

Hordein polypeptides $\mathrm{C} 2$ and $\mathrm{B} 1$ were isolated by gel filtration on Sephacryl S300 as described previously $(21$, section 2.3$)$.

\subsection{Determination of amino acid sequences}

These were made by automated Edman degradation on a Beckman sequencer, Model $830 \mathrm{C}$, using the Beckman programme 122974. Instead of $1.0 \mathrm{M}$-Quadrol, THEED (2) was used in a $0.1 \mathrm{M}$-concentration. The $\mathrm{C} 2$ hordein polypeptide was dissolved in $60 \%$ propanol and total hordein in ethanol $-88 \%$ formic acid $(7: 3$ $\mathrm{v} / \mathrm{v}$ ). In neither case was complete dissolution of the polypeptide achieved. After centrifugation the clear supernatant was introduced into the cup.

Identification of phenylthiohydantoin (PTH)amino acids was done by high performance liquid chromatography (HPLC) using a HewlettPackard chromatograph Model 1084B, equipped with an RP-8, $10 \mu \mathrm{m}$ reverse phase column. The PTH-amino acids were eluted with a linear gradient from $0.01 \mathrm{M}$-sodium acetate buffer, $\mathrm{pH}$ 4 - acetonitril - methanol $(9: 1: 1 \mathrm{v} / \mathrm{v})$ (as the A eluant) to methanol-water $(9: 1 \mathrm{v} / \mathrm{v})$ (as the $B$ eluant). In some cases the identification was confirmed by thin-layer chromatography on polyamide sheets (17).

\subsection{Carboxypeptidase $Y$ digestion}

Carboxypeptidase Y digestion was performed essentially as described previously (21), incubating $2.5 \mathrm{mg}$ of $\mathrm{C} 2$ hordein with $1.5 \mu \mathrm{g}$ carboxypeptidase $\mathrm{Y}$ and $12 \mathrm{mg}$ of total hordein with $12 \mu \mathrm{g}$ carboxypeptidase $\mathrm{Y}$. 
C2-horde in $\mathrm{H}_{2} \mathrm{~N}$-Arg-Gln-Leu-Asn-Pro-Ser-Ser-GIn-Glu-Leu-X -Ser-Pro-Gln-GIn-

total horde in

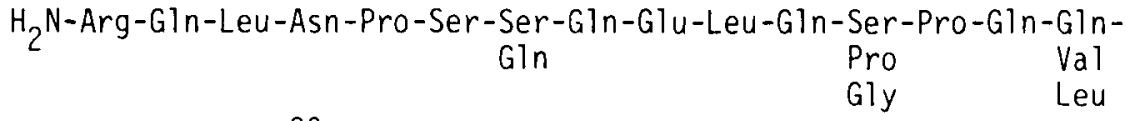

20

total hordein

$$
\begin{array}{lcc}
26 & & 30 \\
\text { Pro-Tyr-Leu-Gln-Gln-Pro-Tyr-Pro-GIn-Asn- } & \text { X } & - \text { Tyr-Leu-Glu- } \\
\text { Ser } & \text { Pro } & -G l y- \\
& G l n & \text { Pro }
\end{array}
$$

Figure 1. The $\mathrm{N}$-terminal amino acid sequences of the $\mathrm{C} 2$-hordein polypeptide and a total hordein preparation.

Repetitive yields were in both cases about $98 \%$, based on the leucine content in position 3 and 10. Molar ratios have not been determined for the amino acids in positions where more than one amino acid was observed. The variation in recovery of the PTH-amino acids precludes a meaningful interpretation of such an analysis.

\section{RESULTS}

Edman degradation of the purified $\mathrm{C} 2$ hordein polypeptide in the sequencer yielded the single amino acid sequence presented in Figure 1. Assuming a molecular weight of 50.000 (14) for the polypeptide and disregarding that only part of the polypeptide was dissolved, the initial yield was at least $20 \%$. Sequencing beyond residue 25 was not possible and the amino acid at position 11 remained unidentified.

The purified BI polypeptide was unaccessible to Edman degradation in the sequencer.

When a preparation of total hordein was subjected to automated Edman degradation a sequence was obtained which was identical to the C2 polypeptide sequence (Figure 1) up to residue 25. The sequence identified the amino acid in position 11 as glutamine and yielded information up to residue 31 . One or two amino acids in addition to the one characteristic for the $\mathrm{C} 2$ polypeptide were present at steps 7,12,15 and 16. Three amino acids were found in position 27 and two in position 31 . Repetitive yield was $98 \%$, but the build-up of background prevented a meaningful interpretation of the results beyond step 31 .

It has previously been shown that the isolated hordein polypeptides $\mathrm{C} 2$ and $\mathrm{B} 1$ release different amino acids when treated with carboxypeptidase $\mathrm{Y}$ in the presence of SDS (21). The sequence -Gly-Val-COOH could be deduced for the B1 polypeptide. The amino acids valine, serine, methionine and isoleucine were liberated from the $\mathrm{C} 2$ polypeptide, but the kinetics were not readily interpretable with respect to sequence. We therefore reinvestigated the $\mathrm{C} 2$ polypeptide, optimizing the enzyme/substrate ratio. The result is shown in Figure 2. Slightly more than one serine was released per polypeptide chain, assuming a molecular weight of 50.000 (14). This may indicate two serine residues near the carboxy-terminus. Since there exists some uncertainty about the true molecular weight (see discussion), this result has to be interpreted with caution. With this reservation in mind we suggest the sequence (Ser, Ile)-Ser-Met-Val$\mathrm{COOH}$ for $\mathrm{C} 2$ hordein.

Digestion of total hordein yielded only the amino acids already found in the $\mathrm{B} 1$ and $\mathrm{C} 2$ polypeptides (Figure 2).

\section{DISCUSSION}

Edman degradation of the isolated hordein polypeptide $\mathrm{C} 2$ yielded a single sequence. The amino terminal sequence obtained from a total hordein preparation was identical with the $\mathrm{C} 2$ sequence but up to three different residues were released at steps, $7,12,15,16,27$, and 31 (Figure 1). The high purity of the $\mathrm{C} 2$ polypeptide as judged by gel electrophoresis (21) gives us confidence that the sequence reported derives from authentic hordein. Among the amino acid residues identified there are about $54 \%$ 

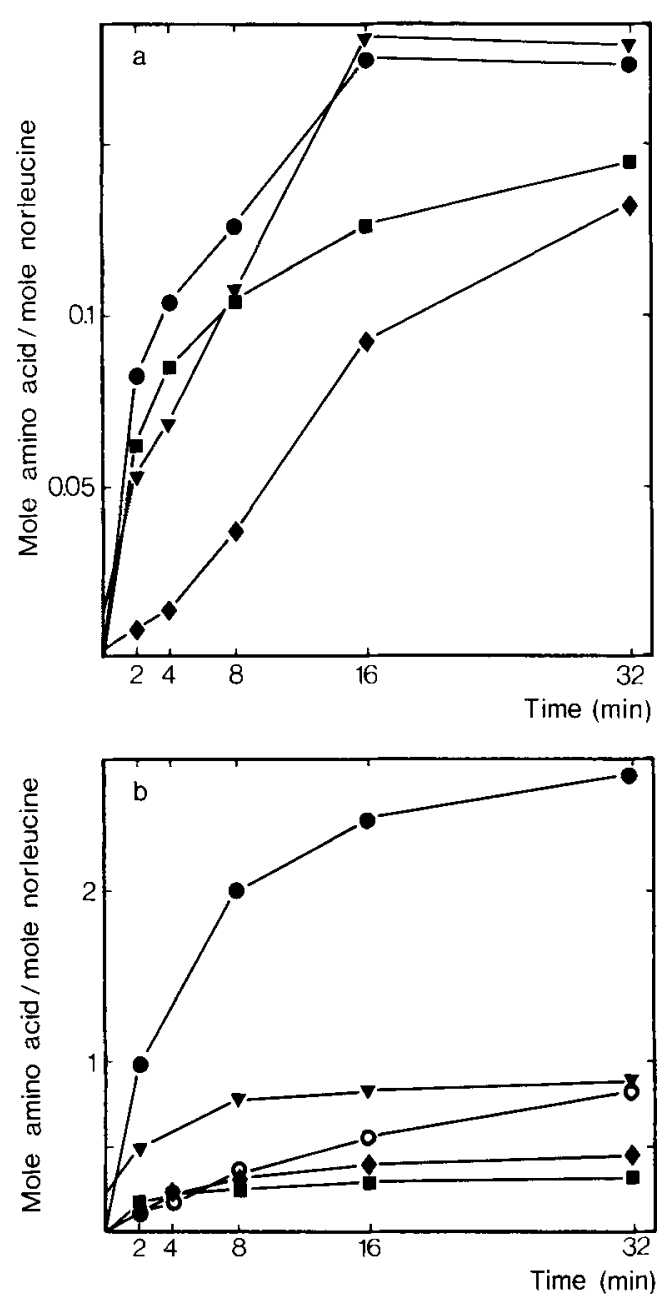

Figure 2. Time course of carboxypeptidase $Y$ digestion of the $\mathrm{C} 2$ hordein polypeptide (a) and the total hordein preparation (b).

Val $(\bullet)$, Ser $(\nabla)$, Met $(\boldsymbol{\nabla})$, Ile $(\bullet)$, Gly $(0)$.

$\mathrm{Gln}+\mathrm{Glu}+$ Pro. The high content of these amino acids is diagnostic for hordein and compares favourably to the $68.5 \% \mathrm{Glx}+$ Pro which has been found by amino acid analysis (21). Comparison with amino terminal sequences of prolamins from hexaploid and tetraploid wheat (4), rye, Aegilops squarrosa (1) and maize (5), respectively, revealed no obvious sequence similarities. An amino terminal sequence has recently been obtained for a total hordein preparation of the barley line Hiproly by BIETZ
(3). Up to step 28 this sequence is identical to the one reported in the present paper.

It is interesting that the $\mathrm{C} 2$ component yielded a unique sequence through 25 steps, although gel electrophoresis shows that it consists of two closely migrating polypeptides (21). From the reinvestigation of the carboxy terminus under optimized conditions a single sequence could be derived (Figure 2). This suggests that either one of the two chains is blocked to Edman degradation or they differ in the part of the polypeptide chain not yet analysed.

From total hordein two or three different amino acids were released at steps $7,12,15,16$, 27, and 31 upon Edman degradation. This can be due to the presence of a minimum of three polypeptides with closely similar $\mathrm{N}$-terminal sequences. If each of the additional amino acids represents a separate chain ten polypeptides can be expected in the mixture. Considering all possible combinations the unlikely number of 216 polypeptides is obtained.

Treatment of the total hordein preparation with carboxypeptidase $Y$ released isoleucine, serine, methionine, glycine, and valine (Figure 2). All of these residues have been found at the carboxy terminus of the $\mathrm{B} 1$ and $\mathrm{C} 2$ polypeptides, respectively. Other amino acids have been released in trace amounts only. Thus, no further indication of heterogeneity is found by carboxy terminal analysis.

In the carboxypeptidase $\mathrm{Y}$ experiments with the purified hordein polypeptide Bl the Cterminal valine was released in super-molar amounts when calculated on the basis of the apparent molecular weight as determined by sodium dodecyl sulfate electrophoresis. This implies that the electrophoresis technique overestimated the molecular weights of this hordein polypeptide, as has been observed for instance with collagen, which like the hordeins has a high proline content (13). In the ultracentrifuge studies of Quensel and Svedberg (20) from 1938 the hordein polypeptides sedimented in $65 \%$ alcohol as one narrow, symmetrical peak with a sedimentation coefficient of 2.0 , which was interpreted to signify a molecular weight of 27.500. In ultracentrifugation experiments carried out with T. G. PEDERSEN in this laboratory we found the same sedimentation coefficients for both the total hordein preparation and the 
purified B1 hordein polypeptide. At present it cannot be decided whether the uniform sedimentation characteristics and the widely differing migration velocities in the SDS electropherograms are due to the special behaviour of a series of hydrophobic polypeptides with similar or dissimilar size.

Characterization of the N-terminal blocked B 1 hordein polypeptide is attempted by sequencing fragments obtained by cyanogen bromide cleavage. So far a total of 30 residues have been located in two cyanogen bromide fragments showing that this approach is possible.

Hordein consists of a group of polypeptides having storage function but no known enzymatic functions. These polypeptides display considerable genetic polymorphisms as judged by gel electrophoretic techniques (16) and the polymorphisms are thought to reflect permissiveness towards mutations in reserve proteins.

The amino acid variations found among the amino termini of the total hordein polypeptides (Figure 1) were evaluated as to their evolutionary and structural implications. To our surprise, only 5 of the 12 possible amino acid substitutions could be accounted for by single basepair changes (Pro-Gin, $2 \times$ Ser-Pro, Val-Leu, GlnLeu) in their codons. This may indicate constraint in the amino terminal part of the hordein polypeptides as to the type of amino acid substitution which is tolerated by the endosperm cell. We compared further the amino acid substitutions with respect to their probability to be part of an $\alpha$-helical or $\beta$-sheet structure, by the predictive algorithms of CHOU and FASMAN (11). Here the changes can be regarded as conservative: Only at position 27 is there an exchange of an $\alpha$-forming glutamine with an alpha-breaking tyrosine or proline residue. All other substitutions fall into the classes of an $\alpha$-former changed to another $\alpha$-former or strong $\alpha$-former and of an $\alpha$-former converted into an $\alpha$-indifferent residue. The substitution of an indifferent residue, serine, for an $\alpha$-former, glutamine, at step seven would not break the $\alpha$-helix predicted between residues 6 to 11 . The same conclusion is reached for the $\beta$-sheet predictions. Exchanges are primarily observed between $\beta$-formers and from a $\beta$-former to an indifferent residue. The substitution of a $\beta$-breaker, serine, with a $\beta$ former, glutamine, at position 7 is regarded to be of little significance, since these residues are situated within an $\alpha$-helical region (position $6-$ 11).

Based on these considerations, we tentatively propose that the amino termini of the hordein polypeptides available for Edman degradation are under structural constraint. A number of functions of the $\mathrm{N}$-terminal sequences may necessitate these constraints: They could comprise the correct synthesis of the precursors from the different mRNAs (6), their transport across the membrane of the endoplasmic reticulum, suitable cleavage of the prepeptide (9), the optimal packing into dense protein bodies ( 15 , 25 ) or the remobilization of the stored peptides during germination of the grain.

\section{ACKNOWLEDGEMENTS}

We gratefully acknowledge the support of Professor Diter von Wettstein, Professor Martin Ottesen, Dr. Anders Brandt, Dr. John IngVersen and Dr. Brian Martin. Dr. J. A. BIETZ kindly informed us of the results of his sequence work. For technical assistance we are indebted to Bodil. Corneliussen, Lone SørenSEN, Nina Rasmussen and Hanne Them Nielsen.

J. M. Schmitt held a post doctoral fellowship from Deutsche Forschungsgemeinschaft.

\section{REFERENCES}

I. Autran, J.-C., E. J.-L. Lew, C. C. Nimmo \& D. D. KASARDA: N-terminal amino acid sequencing of prolamins from wheat and related species. Nature 282, 527-529 (1979)

2. BegG, G. S. \& F. J. Morgan: A non-volatile buffer with improved performance in automated protein sequencing. FEBS Lett. 66, 243-245 (1976)

3. Bietz, J. A.: Note on the amino-terminal amino acid sequence of hordein. Cereal Chemistry. Submitted.

4. Bietz, J. A., F. R. Huebner, J. E. Sanderson \& J. S. W ALL: Wheat gliadin homology revealed through $\mathrm{N}$-terminal amino acid sequence analysis. Cereal Chem. 54, 1070-1083 (1977)

5. Bietz, J. A., J. W. Paulis \& J. S. Wall: Zein subunit homology revealed through aminoterminal sequence analysis. Cereal Chem. 56, 327-332 (1979) 
6. Brandr, A.: Cloning of double stranded DNA coding for hordein polypeptides. Carlsberg Res. Commun. 44, 255-267 (1979)

7. Brandt, A. \& J. Ingversen: Isolation and translation of hordein messenger RNA from wild type and mutant endosperms in barley. Carlsberg Res. Commun. 43, 451-469 (1978)

8. Cameron-Mills, V. \& J. Ingversen: In vitro synthesis and transport of barley endosperm proteins: Reconstitution of functional rough microsomes from polyribosomes and stripped microsomes. Carlsberg Res. Commun. 43, 471489 (1978)

9. Cameron-Mills, V., J. Ingversen \& A. Brandt: Transfer of in vitro synthesized barley endosperm proteins into the lumen of the endoplasmic reticulum. Carlsberg Res. Commun. 43. 91-102 (1978)

10. Cameron-Mills, V., A. Brandi \& J. Ingversen: The molecular biology of barley storage protein synthesis. In: Int. Conf. on Cereals for Food and Beverages: Recent Progress in Cereal Chemistry and Technology. Copenhagen 1979.

11. Chou, P. Y. \& G. D. Fasman: Prediction of the secondary structure of proteins from their amino acid sequence. Adv. Enzymol. 47,pp. 45. (1978) (A. Meister ed.) J. Wiley \& Sons.

12. Dou, H. \& A. H. D. Brows: Hordein variation in wild (Hordeum spontaneum) and cultivated (H. vulgare) barley. Can. J. Cytol. 21, 391-404 (1979)

13. Freytag, J. W., M. E. Noelken \& B. G. HuDson: Physical properties of collagen-sodium dodecyl sulfate complexes. Biochemistry 18 , 4761-4768 (1979)

14. Holder, A. A. \& J. Ingversen: Peptide mapping of the major components of in vitro synthesized barley hordein: Evidence of structural homology. Carlsberg Res. Commun. 43, 177-184 (1978)

15. Ingversen, J.: Structure and composition of protein bodies from wild type and high lysine barley endosperm. Hereditas 81, 69-76 (1975)
16. Jensen, J., J. H. Jørgensen, H. P. Jensen, H. Giese \& H. Doll: Linkage of the hordein loci Hor 1 and Hor 2 with the powdery mildew resistance loci $\mathrm{Ml-k}$ and $\mathrm{Ml-a}$ on barley chromosome 5. Theor. Appl. Genet. In press.

17. KULBE, K. D.: Rapid separation of phenylthiohydantoin (PTH) amino acids by thin-layer chromatography on polyamide glass plates. Anal. Biochem. 44, 548-558 (1971)

18. Miflin, B. J. \& P. R. Shewry: The biology and biochemistry of cereal seed prolamins. In: Seed protein improvement in cereals and grain legumes. International Atomic Energy Agency. pp. $137-158$ (1979)

19. Oram, R. N., H. Doll \& B. Kole: Genetics of two storage protein variants in barley. Hereditas 80, 53-58 (1975)

20. Quensei., O. \& T. Svedberg: Studies on the brewing process by means of ultracentrifugal sedimentation, diffusion and electrophoresis measurements. Compt. Rend. Trav. Lab. Carlsberg, Chimique 22, 441-448 (1938)

21. Schmitr, J. M.: Purification of hordein polypeptides by column chromatography using volatile solvents. Carlsberg Res. Commun. 44, 431-438 (1979)

22. Shewry, P, R., J. R. S. Ellis, H. M. Pratt \& B J. Mifuin: A comparison of methods for the extraction and separation of hordein fractions from 29 barley varieties. J. Sci. Fd. Agric. 29. 433-441 (1978)

23. Shewry, P. R., H. M. Pratt, R. A. Finch \& B. J. MIFL.IN : Genetic analysis of hordein polypeptides from single seeds of barley. Heredity 40 . 463-466 (1978)

24. Solari, R. M. \& E. A. Favret: Polymorphism in endosperm proteins of barley and its genetic control. In: Proc. 2nd Int. Barley Genet. Symp. Ed. R. A. Nilan. Washington State Univ. Press pp. 23-31 (1971)

25. Wettstein, D. von: Biochemical and molecular genetics in the improvement of malting barley and brewers yeast. In: Proc. 17th European Brewery Convention Congress, Berlin 1979. 